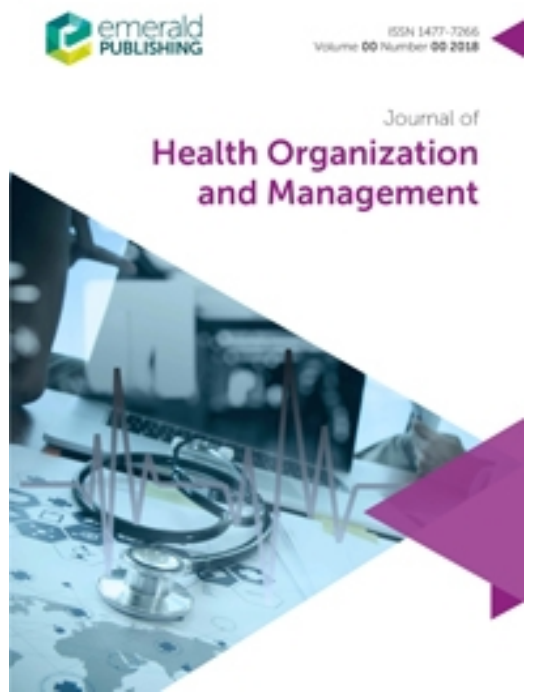

\title{
Lean implementation within healthcare: imaging as fertile ground
}

\begin{tabular}{|r|l|}
\hline Journal: & Journal of Health Organization and Management \\
\hline Manuscript ID & JHOM-02-2020-0050.R1 \\
\hline Manuscript Type: & Original Article \\
\hline Keywords: & $\begin{array}{l}\text { Lean, Ethnography, Imaging, Implementation, process evaluation, } \\
\text { Organizational Culture }\end{array}$ \\
\hline \multicolumn{2}{|l}{} \\
\hline
\end{tabular}

\section{SCHOLARONE ${ }^{m}$ \\ Manuscripts}




\title{
Lean implementation within healthcare: imaging as fertile ground
}

\author{
Abstract \\ Purpose - The purpose of this paper is to understand the barriers and enablers to Lean \\ implementation as part of an imaging quality improvement programme, from a socio-cultural \\ perspective.
}

Design/methodology/approach - An in-depth 33 month ethnographic study, using observation and qualitative interviews, examined the process of Lean implementation as part of an improvement programme.

Findings - Implementation of Lean was more successful compared with other reports of Lean in healthcare settings. Key enablers of Lean were high levels of multidisciplinary staff involvement and engagement; the professional credibility of facilitators; clinicians as early adopters; all within a wider culture of relatively strong inter-professional relationships in the imaging department. These enablers combined with the more routinised and standardised nature of imaging pathways compared to some other acute specialties, suggest that imaging is fertile ground for Lean, linked to the manufacturing origins of Lean.

Practical implications - When introducing Lean within healthcare settings special attention needs to be paid to the specific healthcare context and the existing cultures of inter-professional relationships. Fostering an improvement culture and engagement with training, together with adequate financial resource, are key to contributing to the level of acceptability of an improvement tool such as Lean.

Originality/value- This ethnographic study, bringing together rich multi-source data, has provided a detailed insight into the cultural workings of the process of Lean implementation within a complex healthcare system. 
Keywords Lean; ethnography; imaging; implementation; process evaluation; organizational culture.

Paper type Research paper 


\section{Introduction}

The management philosophy and methodology of Lean has often been cited as a panacea for waste and inefficiency within healthcare delivery (Ben-Tovim, 2007; White, 2006). Originating from the Toyota Motor Corporation during the 1940s onwards, Lean focuses on improving and standardising processes in order to increase customer value and cut out variation and 'waste', defined as nonvalue adding steps in the process, through the systematic use of key tools. Lean has proved popular in manufacturing, seeking to 'reconfigure organizational processes to reduce waste and enhance productivity based upon the application of specialist analytical tools and techniques coupled with creating a culture of continuous improvement' (Womack \& Jones, 1996). Three main aspects of Lean activities are assessment (such as value stream mapping which aims to document and analyse the flow of a process to produce a product or service), improvement (such as Rapid Improvement Events which are held over three to five days and involve staff evaluating and redesigning processes through forms of team problem solving), and performance monitoring (such as visual management tools, standard operating procedures and performance data) (Radnor, Holweg, \& Waring, 2012).

Lean has been increasingly adapted and adopted within healthcare systems over the last 15 years in the UK, USA and elsewhere (D'Andreamatteo, Ianni, Lega, \& Sargiacomo, 2015). Although Lean results have appeared to be promising, there are few reports detailing the outcomes of Lean methods for healthcare (D'Andreamatteo et al., 2015). Challenges in Lean implementation within the healthcare sector have been identified (Brandao de Souza, 2009; Gubb, 2009; Moraros, Lemstra, \& Nwankwo, 2016; Radnor et al., 2012, ). There is some evidence to suggest that the translation of Lean from the private to the public sector in the UK, specifically to the UK National Health Service (NHS) has been difficult. This is due to the mechanisms of NHS funding, with no clear definition of 'customer value', and the application of Lean on a small scale, as a tool-based approach rather than a systems-wide approach (Radnor et al., 2012). Other cultural barriers to the implementation of Lean in healthcare are 'changing mindsets' (Robinson, Radnor, Burgess, \& Worthington, 2012) and 
staff resistance to change (Anthony et al 2019). The deep cultural differences between clinical communities, who favour the randomised controlled trial as the gold standard, and management communities who prefer 'quick win' service improvement methods has been identified as a particular barrier (Young \& McClean, 2009). There is some evidence to suggest that the application of Lean has been regarded by clinical staff with scepticism (Thanos, Zoe, \& Yasmin, 2011) and has been met with resistance by them, bringing to the fore tensions between clinicians and service leaders around the social organization of healthcare work (Waring \& Bishop, 2010). The institutional boundaries between different health care occupations (Stanton et al., 2014), the siloed structure of healthcare organizations, the professional power of the medical profession and the fire-fighting mentality of managers, have also been identified as barriers to the implementation of Lean that advocates a multidisciplinary, 'bottom-up' approach (Luciano Brandao de Souza \& Pidd, 2011).

In the Lean Iceberg Model of successful, sustainable Lean transformation the cultural aspects of leadership, strategy and alignment, and behaviour and engagement have been identified as important enablers of Lean implementation but are often not visible, 'below the waterline' (Hines, Found, Griffiths, \& Harrison, 2008). This is supported by findings of a review identifying leadership, organizational culture, communication as key readiness factors for lean implementation in healthcare (Al-Balushi et al 2014) and there is some indication that a greater number of barriers and enablers relate to cultural aspects of the implementation and sustainability of Lean in comparison to technical aspects, such as tools and techniques (Dos Reis Leite, Bateman, \& Radnor, 2016). However, there is a lack of socio-cultural research exploring in detail Lean implementation within healthcare (Waring \& Bishop, 2010), despite the increase in evaluative research more generally. This points to the need for more ethnographic research to aid an in-depth understanding of the process of applying Lean in complex healthcare organizations. 
Based on findings from an ethnographic study we examined the process of Lean implementation as part of an imaging improvement programme, with the aim of understanding cultural barriers and enablers to Lean implementation within a complex healthcare context. Lean was used as the underlying approach in an imaging quality improvement programme, in a UK National Health service teaching hospital, referred to as an 'improvement programme' throughout this paper.

Imaging services are of critical importance to the wider healthcare system due to the role they play in the diagnosis, treatment, referral and ongoing monitoring of disease. Therefore, transformation of imaging services has the potential to improve the efficiency of the healthcare system as a whole. However, the diverse nature of imaging services and the wide number of stakeholders involved (including radiographers, radiologists, referring clinicians, etc.) can create many challenges in improving patient pathways. Medical imaging involves a team made up of radiologists, radiographers, medical physicists, nurses and biomedical engineers, and other support staff (World Health Organization, 2018). While the role of radiographers is patient-facing, traditionally radiologists have tended to have less direct patient contact, providing essential diagnostic support to other hospital clinicians as well as external agencies, such as primary care. However interventional radiologists, part of a relatively new sub-specialty of radiology that provides minimally invasive image-guided diagnosis and treatment of disease, have more direct patient contact.

We describe the methodological approach and the research setting to provide some context and discuss the ways in which Lean implementation changed over the course of the programme. We then discuss the cultural enablers and barriers of implementation and address the challenges of embedding a Lean philosophy of continual improvement within the culture of the organization as a whole before bringing the findings together in the final discussion. One of the principal limitations of Lean research in healthcare to date is the focus on reducing costs (Schonberger, 2018) rather than taking a more holistic, multistakeholder view (Smith et al, 2020). A large financial investment in an 
imaging improvement programme provided the opportunity to study the process of investment, linked with Lean methodology structures, from a multistakeholder perspective.

\section{Methods}

The overall evaluation was concerned with how a new initiative consisting of equipment (in the form of scanners) and behaviour change (in the form of improving, developing and implementing new clinical pathways) might be embedded in the wider hospital economy. One important facet of that process was reliance on Lean as an underlying management philosophy and change agent. This paper reports on that aspect of the overall implementation programme.

\section{Setting}

The ethnography took place in a prominent UK NHS teaching hospital, a large and complex healthcare organization, spread across multiple sites. The hospital has 16,200 staff and around 1,300 beds, serving a diverse patient population from a deprived inner-city area. The imaging department carries out approximately 425,000 imaging examinations each year. The imaging improvement programme spanned a four-year period and was funded through a $£ 10$ million grant award from a local health charity. The overall programme aimed to install new imaging technology, transform the design and implementation of imaging services provided to primary and secondary care and transform culture and ways of working, in order to improve patient experience and achieve significant health service cost savings. The imaging improvement programme brought together clinical, management and research disciplines with Lean proposed as a managerial approach to facilitate the implementation of the programme.

\section{Data collection}


An ethnographic approach to data collection and analysis was taken through immersion of three evaluation researchers within the day to day interactions of the imaging improvement programme implementation team (referred to as 'the implementation team' throughout this paper). The work of the implementation team within the wider clinical and organizational context was observed over a 33-month period from September 2015- June 2018. Using a triangulation approach, data was analysed from multiple sources consisting of observation fieldnotes, programme documents and qualitative interviews with key stakeholders. Ethical approval for this study was obtained from an NHS research ethics committee. Staff involved with the imaging improvement programme were aware that the evaluation was embedded within the programme and the evaluation researchers were always introduced as 'members of the evaluation team from the University' at meetings and when encountering new members of staff. All members of staff who participated in recorded interviews provided written consent.

Senior management facilitated access for the three researchers (initials withheld from blinded manuscript) to attend and observe a range of meetings. The core implementation team consisted of approximately 11-13 members of staff at any one time, made up of senior managers, project managers and support staff such as data analysts and administrators. Observations were carried out during attendance at 177 meetings and events, including team meetings, team 'huddles', pathwayspecific meetings, performance meetings and board meetings, Rapid Improvement Events, and staff celebration events. Although the researchers attended the meetings largely in a non-participant observer role, they would often comment on or become involved in discussions. Detailed field notes were taken during the meetings, alongside reflective notes. The researchers would also engage staff in informal conversation, for example to clarify issues or to request an update on the progress of pathways. 
Senior management also facilitated access to the imaging improvement programme documents, with researchers given electronic access to programme files and included on email circulation lists. Documents included programme reports, presentations, meeting minutes, clinical pathway diagrams, performance meeting 'dashboards' displaying key data and performance indicators, and guidance documents.

\section{Interviews}

Based on the staff members attending the meetings and events that were observed over the course of the programme, key stakeholders were identified by the researchers. Key stakeholders included staff from the implementation team (including project managers and other members of staff supporting data analysis, research governance, patient recruitment and programme communication) and clinicians, mainly specialist radiologists and radiographers, and senior managers in the imaging department and external management consultants working with the imaging department. These key stakeholders were invited by email, with a participant information sheet attached, to participate in a recorded face to face interview by one of the three researchers. Sixty key stakeholders were invited to participate and 53 agreed, with only seven participants not responding after a follow-up email. The 53 participants took part in at least one interview, with 17 key members of the implementation team, specialist radiologists and radiographers also participating in a follow up interview over the course of the programme (see table 1). All interview participants gave signed consent. Interviews were carried out in a private meeting room in the hospital and were digitally recorded and transcribed verbatim. Interviews were based on a broad topic guide, which was adapted depending on the role of the participant and evolved as the improvement programme progressed from the initial set up through to the main implementation phase. Main questions covered the professional role of the participant; their role in relation to the programme; views and experiences on the role of Lean in the programme; barriers and facilitators experienced during the implementation of the changes; successes experienced or improvements that they felt could be made. 
Table 1 about here 


\section{Analysis}

Data were synthesised through a comprehensive process of thematic analysis, aiming to elicit the salient themes, enablers, barriers and complexities surrounding the implementation of the imaging improvement programme. A hybrid approach of inductive and deductive analysis was carried out in line with the approach taken by Fereday \& Muir-Cochrane, 2006). Interview transcripts and observation fieldnotes were processed using NVivo (QSR, 2012). Data were coded through detailed reading by the researchers, in close collaboration with the other members of the evaluation team, using an inductive approach. The evaluation team met regularly to reflect on the data and identify and discuss emerging themes in an iterative process. These themes were cross-checked across the interview data, observation fieldnotes and documentary data. An overarching conceptual framework was refined to enable the data to be synthesised to examine relationships between themes and develop explanatory accounts for the data. This drew on a more deductive approach, with the research team drawing on their prior knowledge of the relevant literature and their professional experience. As part of a process of participant validation, preliminary findings were presented in written reports and oral presentations to members of the implementation team who provided feedback and discussion.

\section{Findings}

\section{Setting the Lean scene}

Lean was the managerial philosophy underlying the imaging improvement programme, particularly in relation to the wider aim of transforming culture and ways of working. As the implementation of the imaging improvement programme progressed, the Lean approach took a change of direction. Initially, a service improvement manager was recruited and positioned within the imaging department. A more senior programme manager with Lean expertise was also recruited, regarded 
by some as a 'Lean champion'. Some relatively small-scale service improvement projects took place using Lean methods. For example, in the magnetic resonance imaging (MRI) department several improvements were implemented based on staff feedback through a questionnaire identifying problems with processes and suggestions for solutions. Staff reported that the changes resulted in more efficient processes for booking patient appointments and vetting requests for MRI scans using a dedicated vetting radiographer to ensure all scan requests were appropriate.

At the start of the imaging improvement programme both clinical and management staff took part in some 'Lean awareness' training, including radiographers, members of the implementation team, senior managerial staff and administrative staff. The training was a combination of face-to-face and online and was carried out by an external private training company. However, some interview participants who had undergone this training were critical of it (see the quote below), stating that it had not been tailored to staff with a clinical background and had not addressed the use of Lean specifically within a healthcare context. Rather than succeeding in educating and engaging clinical staff in the philosophy and methods of Lean, for some this generic training appeared to act as a barrier, reinforcing a 'divide' between what was viewed as the realm of clinicians and the realm of managers, with Lean perceived as something 'managers do'.

There was an issue with the (external Lean) trainer who wasn't very familiar with the clinical environment, they'd done management... the staff that enrolled were all nurses and radiographers so for them that management kind of head wasn't there and they found the training a bit confusing... and (the staff) sort of probably felt that this was all, you know, superfluous to their day job... the nursing staff not really feeling engaged with what the management kind of side of things were.

(Service Improvement Manager, ID 201) 
Senior managers who attended this training were also highly critical, stating that it had not been pitched at the right level.

I did a two-day green belt (Lean course). My honest experience of that... was probably next to useless. (The trainer) kept getting it wrong. It was all very uncomfortable. So those two days were pretty awful and I would say I didn't really learn anything other than that Leanwell no, I didn't learn anything, he just reinforced the things about cutting out waste. (Senior manager in imaging improvement programme implementation team, ID 198)

However, partly due to the problems identified with the training and the smaller scale application of Lean, a major change was made to the Lean approach approximately halfway through the four-year imaging improvement programme. Although not part of the initial plan for the improvement programme, the decision was taken by the senior managers in the implementation team to accept an opportunity to work in partnership with an external industry-sponsored consultancy team (referred to throughout this paper as 'the consultancy team') to implement larger scale service improvements. The consultancy team were part of a larger technology company who supplied equipment to the imaging department. Interview data indicated that from the outset this partnership was viewed by both parties as being of mutual benefit, with the imaging department identifying benefit from the expertise of the consultancy team, which in turn was viewed as providing the consultancy team with the opportunity to work with a large, prominent teaching hospital. The partnership aimed to achieve sustainable improvements, on a wider-scale using a more structured Lean approach, which we refer to as the second phase of Lean work. The consultancy team used various Lean techniques, including value stream analysis, process mapping and analysis of performance data, with the main method being Rapid Improvement Events. The consultancy team also provided training and support for a number of staff to enable them to run and facilitate RIE 
events themselves, as part of the aim of achieving sustainable changes through instilling a culture of continual improvement.

Some change of staff roles within the implementation team also took place during this period. The 'Lean Champion' programme manager left and an imaging transformation programme manager was recruited specifically to work with the industry-sponsored consultancy team along with the service improvement manager (who remained in the role that they had been in since the start of the programme). Consultancy team members with technical and clinical imaging experience worked with the implementation team to organise and facilitate approximately ten RIEs over a one-year period (see box 1 for the issues and processes addressed in the RIEs). The RIEs generally took place over one week and aimed to bring together members of staff from all disciplines and all levels who were involved in the specific process being addressed by the RIE. Each RIE generally followed the format of discussing and agreeing on the problem to be tackled, discussing the solutions, followed by an agreement of a focused action plan and then testing some or all of these changes, followed by implementation before the end of the RIE and a plan to measure and review the impact of the changes implemented. In total these RIEs involved 97 members of staff from the imaging department, including administrative, clinical and managerial staff from all levels. Twenty-seven of these staff members, mainly radiographers, took part in training provided by the consultancy team, to enable them to take the lead with facilitating RIEs. Both the observation and interview data indicated that the implementation team largely regarded the RIEs as an overall success with data presented to support this, for example in terms of financial savings and reduction of patient 'Did Not Attend' (DNA) rates and waiting times (see table 2 for examples of successes reported as a result of the RIEs). 
Box 1 about here

Box 1: Issues and processes addressed by each of the Rapid Improvement Events

- Data management and performance reporting

- $\quad$ Reporting of scans by Radiologists

- Nuclear medicine- referrals and vetting

- $\quad$ Computed Tomography (CT)- requesting and booking scans

- Ultrasound- patient flow

- Interventional radiology- stock management, pre-assessment of patients, appointment booking and scheduling

- Head and neck cancer pathway

- 2 RIEs on booking and scheduling in Magnetic Resonance Imaging (MRI), CT and Ultrasound

Table 2 about here 


\section{Lean implementation enablers and barriers}

\section{- Multi-professional staff engagement and facilitator credibility}

Over the course of the second phase of Lean implementation an important enabler was the increase in the level of staff engagement in the improvement programme. Here we refer to staff engagement as a collective, team-level experience (Salanova, Agut, \& Peiró, 2005; Schaufeli \& Salanova, 2011). Engagement among clinicians in particular appeared to increase due to their direct involvement in RIEs. Participants discussed the RIEs in terms of the service improvement outcomes. For example, patient access to scanning was reported to have improved through identifying additional capacity in Ultrasound and Computed Tomography, and the number of patients not attending appointments was reduced in diagnostic and interventional radiology through a redesign of the referral and scheduling processes. These reported successes were attributed to the more structured format of the RIE methodology but also to the imaging expertise of the industry sponsored private consultancy team. This clinical expertise and credibility appeared to lead to a greater level of acceptance of the management consultancy team by staff from the imaging department and the ability to work in closer partnership, than would have been the case had they been from a general management background.

[The consultancy team] have used a really good approach which is they've taken their imaging expertise and they've buddied up with people who've got transformation expertise. We also, you know [the Director] agreed to fund [the Service Improvement Senior manager], without [him] I don't think we could have done it,.... I think [an external management consultancy firm] would have got much more resistance... [the department] were ready, it was the right kind of partnership.

(Senior manager in imaging improvement programme Implementation team, ID 198) 
The second phase of implementation, working in partnership with the consultancy team, meant service improvements involved more staff on a much wider scale. This consisted of both clinicians and managers as well as other groups, such as administrators and receptionists, aiming to engage them on an equal footing.

Box 2 about here 
Box 2: Fieldnotes from initial workshop with staff from the Imaging Department ran by the management consultancy team, March 2017

General reflections- High number of senior staff from Imaging department met together for a day and half. Most people appeared engaged with the process and there was a high level of participation.

Mixture of discussion and group work and brief presentations, guided by 5 facilitators from management consultant company, 20 staff members (radiographers, radiologists, nurses, managerial, admin, finance etc)

.....General reflections of staff at the closing of the event on day 2 :

Senior programme manager: We have recognised the silos- we don't often get a chance to all get together in the same room.

Senior nurse: We have involved nursing- we need to do this more.

Senior manager, Radiology: I feel positive, feels like I've been talked to rather than talked at.

Together we are walking away with a plan.

Facilitator: I will be here over the next 9 months and my colleagues are very keen to be involved. 6 weeks working together to prepare for the first RIE.

People spoke enthusiastically. Senior programme manager thanked everybody and said we can make a huge difference.

What was great about (last week's RIE) was everyone who was in there was involved and they were all equal. There wasn't the thing of 'well I'm a receptionist so I can't say anything'. Everyone did have a role to play and with a bit of hard work, I think they could actually come to something that was really good at the end of it. So I think that's really positive and we need to keep that for the next events. 
(Senior Radiographer, ID 235)

Box 3 about here

Box 3: Fieldnotes from implementation team meeting, May 2017

Service Improvement Manager gives an update: 'We had our first Rapid Improvement Event with

12 people involved ... We wanted to look at front end referral processes....It's interesting but

intense, especially bringing together everyone's perspectives, but it's really useful to see how everyone's role fits in'.

The change in approach led to staff reportedly feeling more 'ownership' of the service improvements, in line with a 'bottom-up' approach advocated by Lean. As indicated by the quote below, the service improvement manager reported that initially staff had expected that her role was to tell them how to improve their service. However, over the period of the imaging improvement programme, staff understood that rather than imposing changes on them, her role was to work with them in facilitating service improvements that they identified.

At the start I think people were a bit sceptical because they didn't really know what I was here to do... What happened initially is I think people were expecting me to come up with ideas for improvements and then make them happen but my approach was different, it was not for me to say 'this is what you need to improve in your service' or 'this is how you need to improve your service', it was more like 'what do you think you want to improve'...

(Service Improvement Manager ID 201) 


\section{- Clinicians as early adopters and inter-professional relationships}

From the beginning of the imaging improvement programme many senior clinicians, including senior radiographers and specialist radiologists, were receptive to Lean philosophy and methodology and enthusiastic about the promise of Lean. Interview data showed that clinicians generally expressed support for the need to work in what was described as a 'smarter' way to use resources more efficiently for patient benefit within a climate of increasing financial pressures on health services, as seen below.

So my experience of Lean is that I think it's not intuitive to most people but when you tell them about it, it makes a lot of sense. And once people understand why it's useful to look at a process through the eyes of Lean, if I put it that way, then I think they get quite excited and they find things that are waste and it's amazing how many things that we do just because we've always done it that way and I was taught to do it that way and actually that's how we've always done it, why would you do it differently?...

(Specialist Radiologist, ID 212)

I'm fully signed up to Lean.... I think that is vital, especially with a big complex organization like ourselves.

(Specialist Radiologist, ID 219)

Managers recognised the high level of engagement that many clinicians had with a Lean approach, despite an element of resistance from some before the RIEs took place.

We've got teams that engaged in such a way, that they actually expect a transformation to be part of their job now. And they expect to deliver change - although they might get a bit 
resistant - and some of the people we've chosen have deliberately been, because they've been a bit resistant to change - so we've involved a mix of people. Those that are real change - early innovators if you like, and those that are... a bit cynical, and actually they've gone through the sort of like the change cycle if you like. And they've been on that kind of emotional journey, with us as part of the Rapid Improvement Event...

(Service Improvement Manager, ID 201)

As seen above, members of the implementation team expressed the view that particular clinicians played a key enabling role as 'early innovators', or adopters, in the implementation of Lean thinking. Lean was regarded by some of these 'early adopters' as having the potential to provide a common 'language' between managers and clinicians as well as other groups of staff.

I would make sure everyone knows about Lean, not necessarily for people to use it, you know, although everyone should, it's because I think we should all speak the same language. I don't really understand why someone should have management training and someone should have, you know, receptionist training, someone should have, I don't know, there are other examples, but I think we should all have a common thread of training so we can all speak to each other.

(Specialist Radiologist, ID 212)

The enabling factors of a high level of multidisciplinary staff engagement, the credibility of facilitators and clinicians as early adopters, must be interpreted within the context of a wider culture of relatively strong inter-professional relationships in the imaging department. This was particularly evident between clinical staff and managerial staff including the implementation team. A mutual recognition of the value of others' roles emerged as a prominent theme during the interviews and in the observation data. 


\section{Moving towards a cultural shift}

Interview participants identified the need for embedding a culture of continual improvement within the imaging department and many felt that this process was beginning with the partnership with the industry sponsored consultancy team, as seen in the extract below. The consultancy team trained over 20 staff, mainly radiographers, to enable them to lead RIEs themselves and this was part of a move towards sustaining the service improvements.

Box 4 about here

Box 4: Fieldnotes from imaging improvement programme Board meeting, June 2018

Implementation team senior manager A: The partnership with (Technology/Management consultant company) is to continue..... they get to use (the Hospital Trust) as an example. If we continue this work with them we have a fighting chance of embedding continual improvement. Imaging transformation programme manager: So far 19 staff have been accredited with bronze level for carrying out RIEs, they are very engaged.

Implementation team senior manager A: We need to get to a point where this continual improvement will happen if (Imaging Transformation Programme manager) role isn't there. Implementation team senior manager B: - where people will see the benefit of this (work).

However, the majority of interview participants, both clinical and managerial staff, acknowledged that a cultural shift needed to occur in the healthcare organization as a whole in order to support 
cultural changes within the imaging department. Yet, this system-wide approach was regarded by many as a key challenge. Some staff suggested that although this process of cultural change was beginning, much more work was needed to fully embed Lean thinking within the organization as a whole.

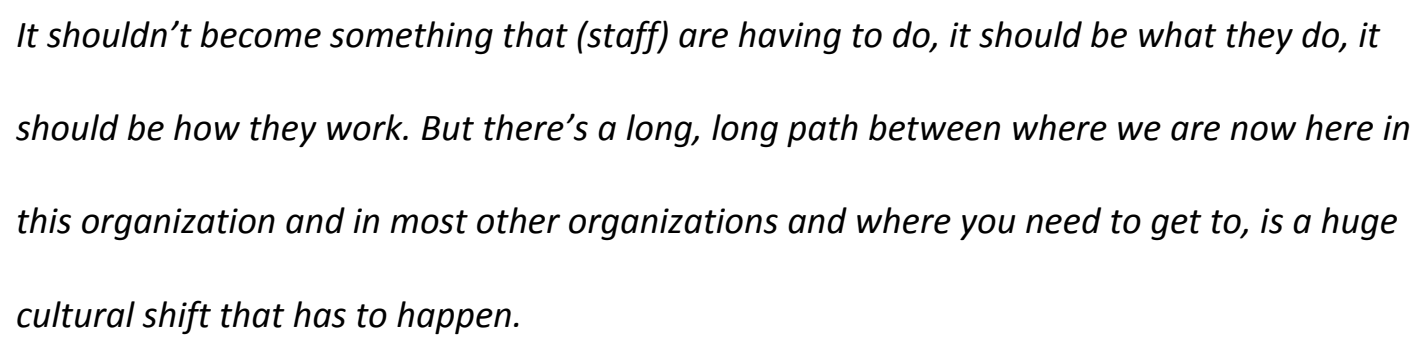
should be how they work. But there's a long, long path between where we are now here in this organization and in most other organizations and where you need to get to, is a huge cultural shift that has to happen.

(Senior member of imaging improvement programme implementation team, ID 198)

The support of senior leadership in the Trust was identified as a key enabler to engaging staff and promoting this cultural change.

\author{
I think that Lean methodology's very good, and it's very - the people that are aware of it, \\ and they've done some training in it, can see how to implement it and how to take it forward \\ and how it's useful. But it's only useful if you have the support.' \\ (Radiologist, ID 239)
}

The main enabler (for service transformation) has to be the high levels of the CEO and all those important executives in the hospital. They should be the main enablers and they should be seen and visible... so you need to walk the shop floor to be seen and to be shown that oh, we really need to do this. This is really pivotal towards our organization, otherwise we're not going to be there for a hundred years or so.

(Member of implementation team, ID 003) 
The imaging improvement programme was regarded as providing essential learning for the implementation of service transformation on an organizational level.

There's a real desire at (hospital) level to do something, to have a cultural change piece around not just using the tools but how do we embed, how do we make the 14,000 people that work here think in a way that is continuous improvement and taking out waste and constantly focusing on the patient.... The (Imaging department) would welcome (Lean) as a way of working going forward and then the ideal would be that it spreads further into the (hospital).

(Senior member of imaging improvement programme implementation team, ID 195)

However, many recognised the particular challenges involved in attempting a cultural shift in a healthcare organization that was large and complex, spread across multiple sites, serving a diverse patient population from a deprived inner-city area. The wider context of financial constraints on the health services was also identified as a barrier to fully embedding a Lean culture within the hospital.

Financially it's quite difficult because you know you might have funding, you know this time next year we might find that the funding, because the kind of pressure on ... finances is so tight, the funding to support some of the stuff that we're trying to do you know which includes releasing people from their day job, it includes funding people like (the Service Improvement manager).

(Senior member of imaging improvement programme implementation team, ID 195) 


\section{Discussion}

Based on findings from an in-depth 33-month ethnographic study we examined Lean implementation as part of an imaging improvement programme, to understand barriers and enablers to Lean implementation within a complex healthcare context, from a socio-cultural perspective. The hybrid approach of deductive and inductive analysis resulted in the emergence of three overarching themes: 'multi-professional staff engagement and facilitator credibility', 'clinicians as early adopters and inter-professional relationships' and 'moving towards a cultural shift'. Each theme contained a balance of barriers and facilitators, at times finely balanced, at times imbalanced. This mix of enabler and barrier meant that the themes were not apportioned into one category or the other. Rather, the ethnographic approach allowed both barrier and facilitator to co-exist within a thematic classification.

Our findings have shown that Lean implementation appeared to be more successful in comparison to other previous reported implementations of Lean in healthcare settings (D'Andreamatteo et al., 2015; Moraros et al., 2016; Radnor et al., 2012). This can be partly attributed to the pre-existing wider culture of favourable inter-professional relationships between clinical and managerial staff in the imaging department. This is linked with the nature of radiology as a specialty that traditionally has less direct contact with patients and more emphasis on team management and strong links with external agencies such as primary care. Radiology specialists tend to be less autonomous and are perhaps therefore less likely to uphold values in line with traditional medical culture associated with individualism and professional dominance (Degeling, Zhang et al. 2006). The finding that favourable inter-professional relationships acted as an important enabler for Lean implementation is supported by previous work demonstrating greater openness to being involved with managerial approaches by clinicians from some other nonacute specialties, including radiology, pathology and psychiatry, in comparison to more acute medical specialties such as gynaecology and paediatrics (Willcocks, 1999). This was attributed to several factors: greater emphasis on team management; less focus on direct 
patient contact and professional individualism; strong relationships with people and external agencies; more exposure to competition from the private sector; better internal forms of communication within departments, for example more opportunities for meetings. Our findings also support a previous study that Lean was met with engagement and enthusiasm by Emergency Department (ED) staff, found to be linked with the less hierarchical culture of the ED compared with other parts of the hospital and the less elevated status of Emergency Medicine compared with other medical specialisms, meaning staff were more receptive to managerialist methods, such as Lean (Timmons et al, 2014). Although Radiology involves far less direct patient contact than Emergency Medicine, both specialisms appear to place more emphasis on team management and less emphasis on professional individualism and hierarchical structures compared with other medical specialisms. This highlights how crucial relational elements and team cohesion are in ensuring the success of an improvement intervention. Greater success in Lean implementation may also have been attributable to the financial context as well as the cultural context with Lean adoption linked to substantial investment in imaging equipment; in contrast, Lean has often been associated with austerity and cost-saving initiatives (Smith et al, 2020).

Furthermore, we suggest that, particularly within imaging departments, the need to purchase and maintain expensive technology, scanners in the case of the imaging improvement programme, gave rise to the development of long-term relationships with the private companies who supplied the equipment. In the current context, this relationship directly led to the partnership with an industrysponsored consultancy team, perceived as having professional credibility due to their imaging expertise. There was increased engagement from staff at all levels with the wider-scale, more structured approach of the consultancy team, facilitated by senior clinicians taking an early adopter role, supporting the finding that the involvement of senior clinical leaders and the empowerment of team members play an important role in Lean implementation (Morrow et al 2014). A mutual recognition of the value of others' roles and the feeling of 'ownership' of the service improvements 
reported by staff is in line with previous analyses of an effective RIE based on longitudinal observation (Hayes et al 2014). However, as stated, it is important that our findings are interpreted within the wider context of pre-existing congenial inter-professional relationships in the imaging department, supporting previous findings that successful Lean implementation is more likely if built on well-established, functional healthcare teams (Ulhassan et al 2014).

Our findings also support evidence from healthcare settings that the success of Lean implementation in healthcare is linked to the cultural factor of 'changing of mindsets' (Robinson et al., 2012) and the sustainability of Lean is linked to the engagement and training of staff (Al-Balushi et al., 2014) and, more generally, that staff engagement has the potential to influence the degree to which there is a culture of improvement within healthcare (Kings Fund, 2012). There is a dearth of evidence of sustained results following Lean implementation in the literature (Woodnutt, 2018) and our findings, although not providing proof of sustainability, suggest that Lean was associated with long term changes related primarily to cultural change and engagement with training (Glasgow, Scott-Caziewell \& Kaboli, 2010).

Our findings suggest that the siloed and hierarchical structure of the NHS and professional power of the medical profession, as well as the fire-fighting mentality of managers, identified as potential barriers to the implementation of Lean (Luciano Brandao de Souza \& Pidd, 2011) Stanton et al 2014), did not emerge as particular barriers to the implementation of Lean within the imaging improvement programme. The high level of clinician engagement with Lean that emerged contrasts with earlier studies indicating disengagement or resistance to Lean implementation by clinical staff (Waring \& Bishop, 2010); Stanton et al, 2014) Thanos et al., 2011). Our findings challenge the large body of literature on the tensions and cultural differences between managers and clinicians more generally (for example Degeling et al., 2006; Llewellyn, 2001; McDonald, Waring, \& Harrison, 2006) Stanton et al 2014), indicating the diversity within health care contexts which has important implications when introducing Lean or any other managerial approaches within healthcare 
organizations. It has been argued that within a healthcare context the professional status and relative autonomy of clinicians leads to a different experience of Lean compared to manufacturing workers, with occupational and institutional demarcation lines and silos of clinicians influencing how Lean is reinterpreted in relation to their professional interests and values (Stanton et al, 2014). However, our findings indicate that these professional demarcations and autonomy of the medical profession did not emerge as barriers in the context of imaging. Further, clinical imaging pathways tend to be time-limited, and more routinised and standardised than pathways in other more acute specialties that are more likely to have to address higher levels of clinical uncertainty and unpredictability. Therefore, the application of a management methodology concerned with standardisation of processes and the minimisation of variance, in line with the origins of Lean in the manufacturing industry, is likely to be more successful in imaging departments than in other clinical specialties. Our findings suggest that imaging is a fertile ground for Lean implementation, contrary to arguments that Lean cannot be applied in healthcare (Radnor et al 2012).

\section{Implications for future practice and research}

We had the privilege of deep ethnographic immersion within 'the field' of the clinical imaging department over almost a three-year period. Therefore, this study brings together rich multi-source data to produce internally valid findings. As with qualitative work more broadly, we do not argue generalizability of findings, however, our findings and resulting implications for practice hold transferability to similar settings. Our study captures perceptions of and learning from the process of Lean implementation. It does not measure Lean's impact on improvement in the setting due to its central interest with the dynamics of implementation. Future work could include attempts at quantification of Lean impact, for instance on waiting list reduction, cost saving, improved administrative and clinical processes and the like. This, in combination with our findings, would help elucidate the extent to which perceptions of Lean and its acceptability as an improvement tool in imaging hold parallels with its measurable efficacy. 
Our findings suggest that fostering an improvement culture, which no doubt takes time to embed, is a key component contributing to the level of acceptability of and openness to an improvement tool such as Lean. Furthermore, the findings suggest that changes introduced into a healthcare setting with adequate financial resource attached are more likely to be favourably received. Our finding that generic training in Lean reinforced divides within the team points to the need for further exploratory research to understand the differential effect of Lean processes on professional and administrative staff. In addition, the identification by the implementation team of the key enabling role of early adopters suggests that it would be beneficial to prioritise prompt identification of these team members.

\section{Concluding remarks}

Our ethnographic study has provided a detailed insight into the cultural workings of Lean within the healthcare system, addressing the paucity of socio-cultural research exploring the implementation of Lean within healthcare (Waring \& Bishop, 2010). Our findings have important implications for operationalizing Lean in a healthcare context. We would recommend caution when implementing Lean and the need to pay particular attention to the specific healthcare context, in line with others who have argued against generically transplanting Lean intact to its original principles (Thanos et al., 2011). Although many interview participants indicated enthusiasm for embedding Lean culture on an organizational level across the hospital, extending Lean implementation across other specialties may be of limited success if the healthcare context does not align at all with the manufacturing origins of Lean, associated with the standardisation of processes and the minimisation of variance. In addition, the existing culture of inter-professional relationships must be taken into account as unfavourable relationships are highly likely to hinder the success of Lean. In some contexts a greater amount of effort may be vital beforehand to engage staff, in order to lay the groundwork for implementing Lean. 


\section{Acknowledgements}

(Withheld from blinded manuscript) 


\section{References}

Al-Balushi, S., Sohal, A. S., Singh, P. J., Al Hajri, A., Al Farsi, Y., \& Al Abri, R. (2014). Readiness factors for lean implementation in healthcare settings-a literature review. Journal of health organization and management, 28(2), 135-153.

Antony, J., Sunder M., V., Sreedharan, R., Chakraborty, A. and Gunasekaran, A. (2019), A systematic review of Lean in healthcare: a global prospective, International Journal of Quality \& Reliability Management, Vol. 36 No. 8, pp. 1370-1391. https://doi.org/10.1108/IJQRM-12-2018-0346 Ben-Tovim, D. I. (2007). Seeing the picture through "lean thinking". BMJ, 334(7586), 169-169. doi:10.1136/bmj.39101.389271.1F

Brandao de Souza, L. (2009). Trends and approaches in lean healthcare. Leadership in Health Services, 22(2), 121-139.

Brandao de Souza, L., \& Pidd, M. (2011). Exploring the barriers to lean health care implementation. Public Money \& Management, 31(1), 59-66. doi:10.1080/09540962.2011.545548

D'Andreamatteo, A., lanni, L., Lega, F., \& Sargiacomo, M. (2015). Lean in healthcare: A comprehensive review. Health Policy, 119(9), 1197-1209. doi:10.1016/j.healthpol.2015.02.002 Degeling, P., Zhang, K., Coyle, B., Xu, L., Meng, Q., Qu, J., \& Hill, M. (2006). Clinicians and the governance of hospitals: A cross-cultural perspective on relations between profession and management. Social Science \& Medicine, 63(3), 757-775. doi:https://doi.org/10.1016/j.socscimed.2006.01.034

Dos Reis Leite, H. V., Bateman, N., \& Radnor, Z. J. (2016). A classification model of the lean barriers and enablers: a case from Brazilian healthcare. Paper presented at the European Operations Management Association Conference Norwegian University of Science and Technology https://dspace.Iboro.ac.uk/dspace-jspui/bitstream/2134/24691/3/Leite_fullpaper_V3.pdf Fereday, J., \& Muir-Cochrane, E. (2006). Demonstrating Rigor Using Thematic Analysis: A Hybrid Approach of Inductive and Deductive Coding and Theme Development. International Journal of Qualitative Methods, 5(1), 80-92. doi:10.1177/160940690600500107 
Glasgow, J., M., Scott-Caziewell, J., R., \& Kaboli, P., J. (2010). Guiding inpatient quality improvement: a systematic review of Lean and Six Sigma. Joint Commission Journal on Quality and Patient Safety, 36(12), 533-540. https://doi.org/10.1016/S1553-7250(10)36081-8

Gubb, J. (2009). Have targets done more harm than good in the English NHS? Yes. BMJ : British Medical Journal (Online), 338. doi:http://dx.doi.org/10.1136/bmj.a3130

J. Hayes, K., Reed, N., Fitzgerald, A. and Watt, V. (2014), Applying lean flows in pathology laboratory remodelling, Journal of Health Organization and Management, Vol. 28 No. 2, pp. 229-246.

https://doi.org/10.1108/JHOM-03-2013-0064

Hines, P., Found, P., Griffiths, G., \& Harrison, R. (2008). Staying Lean: Thriving Not Just Surviving: Lean Enterprise Research Centre, Cardiff University

Kings-Fund. (2012). Leadership and engagement for improvement in the NHS. report from the Kings Fund Leadership, review, Kings Fund, London.

Llewellyn, S. (2001). 'Two-Way Windows': Clinicians as Medical Managers. Organization Studies, 22(4), 593-623. doi:10.1177/0170840601224003

Luciano, B. d. S. (2009). Trends and approaches in lean healthcare. Leadership in Health Services, 22(2), 121-139. doi:doi:10.1108/17511870910953788

McDonald, R., Waring, J., \& Harrison, S. (2006). Rules, safety and the narrativisation of identity: a hospital operating theatre case study. Sociology of Health \& IIIness, 28(2), 178-202.

doi:doi:10.1111/j.1467-9566.2006.00487.x

Moraros, J., Lemstra, M., \& Nwankwo, C. (2016). Lean interventions in healthcare: do they actually work? A systematic literature review. International Journal for Quality in Health Care, 28(2), 150165. doi:10.1093/intqhc/mzv123

Morrow, E., Robert, G. and Maben, J. (2014), Exploring the nature and impact of leadership on the local implementation of The Productive Ward Releasing Time to Care ${ }^{\mathrm{TM}}$, Journal of Health Organization and Management, Vol. 28 No. 2, pp. 154-176. https://doi.org/10.1108/JHOM-01-20130001 
Radnor, Z. J., Holweg, M., \& Waring, J. (2012). Lean in healthcare: The unfilled promise? Social Science \& Medicine, 74(3), 364-371. doi:https://doi.org/10.1016/j.socscimed.2011.02.011 Robinson, S., Radnor, Z. J., Burgess, N., \& Worthington, C. (2012). SimLean: Utilising simulation in the implementation of lean in healthcare. European Journal of Operational Research, 219(1), 188-197. Salanova, M., Agut, S., \& Peiró, J. M. (2005). Linking organizational resources and work engagement to employee performance and customer loyalty: the mediation of service climate. Journal of applied Psychology, 90(6), 1217.

Schaufeli, W., \& Salanova, M. (2011). Work engagement: On how to better catch a slippery concept. European Journal of Work and Organizational Psychology, 20(1), 39-46.

Schonberger, R.,J. (2018). Reconstituting lean in healthcare: from waste elimination toward 'queueless' patient-focused care. Business Horizons, 61, 13-22. doi:10.1016/j.bushor.2017.09.001 . Smith, I., Hicks, C., \& McGovern T. (2020). Adapting Lean methods to facilitate stakeholder engagement and co-design in healthcare. British Medical Journal, 368, m35. doi: https://doi.org/10.1136/bmj.m35 Stanton, P., Gough, R., Ballardie, R., Bartram, T., Bamber, G. J., \& Sohal, A. (2014). Implementing lean management/Six Sigma in hospitals: beyond empowerment or work intensification? The International Journal of Human Resource Management, 25(21), 2926-2940.

Thanos, P., Zoe, R., \& Yasmin, M. (2011). The role of actor associations in understanding the implementation of Lean thinking in healthcare. International Journal of Operations \& Production Management, 31(2), 167-191. doi:doi:10.1108/01443571111104755

Timmons, S., Coffey, F. and Vezyridis, P. (2014), Implementing lean methods in the Emergency Department: The role of professions and professional status, Journal of Health Organization and Management, Vol. 28 No. 2, pp. 214-228. https://doi.org/10.1108/JHOM-10-2012-0203 Ulhassan, W., Westerlund, H., Thor, J., Sandahl, C. and von Thiele Schwarz, U. (2014), Does Lean implementation interact with group functioning?, Journal of Health Organization and Management, Vol. 28 No. 2, pp. 196-213. https://doi.org/10.1108/JHOM-03-2013-0065 
Waring, J. J., \& Bishop, S. (2010). Lean healthcare: Rhetoric, ritual and resistance. Social Science \& Medicine, 71(7), 1332-1340. doi:https://doi.org/10.1016/j.socscimed.2010.06.028

White, C. (2006). "Lean" thinking may cut NHS inefficiencies and improves patient care. BMJ : British Medical Journal, 332(7556), 1472-1472.

Woodnutt., S. (2018). Is Lean sustainable in today's NHS hospitals? A systematic literature review using the meta-narrative and integrative methods. International Journal for Quality in Health Care, 30(8), 578-586. https://doi.org/10.1093/intqhc/mzy070

World Health Organizaton (2018). http://www.who.int/diagnostic_imaging/en/ accessed 3rd July 2018.

Willcocks, S. (1999). Clinical Management and Cultural Diversity: The Cultural Context of Doctor Involvement in the Managerial Process. Health Services Management Research, 12(4), 212-216. doi:10.1177/095148489901200402

Womack, J. P., \& Jones, D. T. (1996). Lean Thinking: banish waste and create wealth in your corporation University of Michigan: Simon and Schuster.

Young, T., \& McClean, S. (2009). Some challenges facing Lean Thinking in healthcare. International Journal for Quality in Health Care, 21(5), 309-310. doi:10.1093/intqhc/mzp038 
Tables:

Lean implementation within healthcare: imaging as fertile ground

Table 1: Interview participants

\begin{tabular}{|l|l|l|}
\hline Professional group & Number participating & Number participating \\
\hline Specialist radiologists & in an interview & follow up interview \\
\hline Other medical specialists & 9 & 2 \\
\hline Radiographers & 6 & 0 \\
\hline Nurses & 9 & 4 \\
\hline Managers & 4 & 0 \\
\hline Implementation team (support staff) & 9 & 7 \\
\hline Industry sponsored private consultancy team & 2 & 0 \\
\hline (partnering with implementation team) & 9 & 0 \\
\hline
\end{tabular}


Table 2: Examples of successes reported as a result of Rapid Improvement Events (RIEs)

\begin{tabular}{|c|c|c|c|}
\hline Department & $\begin{array}{l}\text { Problem tackled by } \\
\text { RIE }\end{array}$ & Key outcomes from RIEs & $\begin{array}{l}\text { Results- comparisons } \\
\text { between rates before RIE and } \\
\text { after }\end{array}$ \\
\hline $\begin{array}{l}\text { Magnetic } \\
\text { Resonance } \\
\text { Imaging } \\
\text { (MRI) } \\
\text { Computed } \\
\text { Tomography } \\
\text { (CT) } \\
\text { Ultrasound } \\
\text { (US) }\end{array}$ & $\begin{array}{l}\text { Inefficient } \\
\text { scheduling of } \\
\text { patient } \\
\text { appointments, } \\
\text { High patient DNA } \\
\text { ('Did Not Attend') } \\
\text { rate }\end{array}$ & $\begin{array}{l}\text { - Established Vetting } \\
\text { Standard Operating } \\
\text { Procedures } \\
\text { - Created crib sheet for } \\
\text { referrers to ensure referrals } \\
\text { were appropriate } \\
\text { - Established escalation } \\
\text { process for vetting referrals } \\
\text { - Switched from fax referrals } \\
\text { to electronic only }\end{array}$ & $\begin{array}{l}\text { - } 13 \% \text { reduction of MRI DNA } \\
\text { rate } \\
\text { - } 21 \% \text { reduction of CT DNA } \\
\text { rate } \\
\text { - } 23 \% \text { reduction of US DNA } \\
\text { rate } \\
\text { - } 17 \% \text { improvement in } \\
\text { routine turnaround booking } \\
\text { (measured } 16 \text { months post } \\
\text { RIE) }\end{array}$ \\
\hline $\begin{array}{l}\text { Acute } \\
\text { reporting of } \\
\text { X-ray and } \\
\text { urgent CT } \\
\text { scans }\end{array}$ & $\begin{array}{l}\text { Backlog of scans } \\
\text { reported by } \\
\text { Radiologists }\end{array}$ & $\begin{array}{l}\text { - Introduction of Flow } \\
\text { Coordinator (FC) role to re- } \\
\text { route and triage calls } \\
\text { - Redesign of central } \\
\text { reporting area to incorporate } \\
\text { workspace for FC and relocate } \\
\text { reporting registrar } \\
\text { - Reduction of phone calls to } \\
\text { Senior Registrar reporting } \\
\text { scans, from } 120 \text { per day to } \\
\text { less than } 10 .\end{array}$ & $\begin{array}{l}\text { - Reduction of report } \\
\text { turnaround time } \\
\text { - } 100 \% \text { of scans reported } \\
\text { within } 2 \text { weeks } \\
\text { - } 48 \% \text { increase in acute X-ray } \\
\text { plain film reporting } \\
\text { productivity } \\
\text { (measured } 13 \text { months after } \\
\text { RIE) }\end{array}$ \\
\hline $\begin{array}{l}\text { Nuclear } \\
\text { Medicine }\end{array}$ & $\begin{array}{l}\text { Inefficient } \\
\text { scheduling and } \\
\text { vetting of patient } \\
\text { appointments, } \\
\text { High DNA rate }\end{array}$ & $\begin{array}{l}\text { - Standardised referral } \\
\text { process } \\
\text { - Introduction of electronic } \\
\text { vetting, instead of paper } \\
\text { - Implementation of weekly } \\
\text { team huddles using visual } \\
\text { management tools } \\
\text { - Developed patient } \\
\text { information leaflet }\end{array}$ & $\begin{array}{l}\text { - } 16 \% \text { reduction of Nuclear } \\
\text { Medicine DNA rate } \\
\text { - } 70 \% \text { reduction in paper } \\
\text { usage for referrals } \\
\text { - Reduction of vetting } \\
\text { turnaround time } \\
\text { (measured } 10 \text { months after } \\
\text { RIE) }\end{array}$ \\
\hline
\end{tabular}

